\title{
Colour Fading of Textile Fabric by Plasma Treatment
}

\author{
H. F. Cheung, C. W. Kan, C. W. M. Yuen, J. Yip, and M. C. Law \\ Institute of Textiles and Clothing, The Hong Kong Polytechnic University, Hung Hom, Kowloon 852, Hong Kong \\ Correspondence should be addressed to C. W. Kan; tccwk@inet.polyu.edu.hk
}

Received 13 November 2012; Accepted 11 December 2012

Academic Editor: Phillip W. Gibson

Copyright (c) 2013 H. F. Cheung et al. This is an open access article distributed under the Creative Commons Attribution License, which permits unrestricted use, distribution, and reproduction in any medium, provided the original work is properly cited.

Colour fading of a reactive dye (C.I. Reactive Blue 19) dyed textile fabric was performed by atmospheric pressure plasma (APP) treatment with the use of plasma jet. Under the APP treatment condition of treatment time $=5 \mathrm{sec} / \mathrm{mm}$; ignition power $=160 \mathrm{~W}$; oxygen concentration $=1 \%$; jet distance $=3 \mathrm{~mm}$, significant colour-fading effect was achieved. For comparison purpose, the reactive dye dyed textile fabric was subjected to conventional enzymatic colour-fading process. Experimental results revealed that the APPinduced colour-fading effect was comparable with conventional enzymatic colour-fading process.

\section{Introduction}

Recently, textile manufacturers start fading textile products which become very popular amongst young customers [1]. Therefore, companies have been trying in recent years to develop various techniques to improve the visual aspect of fabrics especially the faded looks [2-4]. The conventional technologies involve creating designs by fading the colour in certain areas of textile fabric using the processes such as sanding, sand blasting, brushing, prewashing, rinsing, stone washing, sand washing, snow washing, stone washing with enzymes, and bleaching $[5,6]$. Although desired fading effect could be achieved by such methods, the following problems were encountered: (i) difficulty in application and time consuming due to problem in work flow; (ii) decrease in the wear resistance of the product; (iii) inability to create standard and reproducible designs; (iv) successful application of designs is not possible on all textile surfaces; (v) inability to create required nuances in shading; (vi) inability to produce identical fading effect on both sides of the products; (vii) loss of quality [7-9]. In addition, the production of faded looks in fabric using conventional technologies involves large amount of water and most of which being highly contaminated by chemical products used in the process. Also the timeconsuming and old-fashioned processes are not suitable for mass production and increase the production cost [7-9]. In order to cope with these problems, a novel system that does not have the drawbacks involved in the conventional technologies should be adapted for treating the textile fabrics. The plasma treatment, being a dry treatment, would be an alternative to conventional technologies. This paper will investigate the use of atmospheric pressure plasma treatment for fading colour from textile fabrics.

\section{Experimental}

2.1. Materials. $100 \%$ cotton single jersey-knitted fabric was used (fabric weight $=220 \mathrm{~g} / \mathrm{m}^{2}$; yarn count $=32 \mathrm{~S} / 2$ ). The cotton fabric was dyed with C.I. Reactive Blue 19 under industrial condition. After dyeing, the cotton fabric was conditioned at $65 \pm 2 \%$ relative humidity and $21 \pm 1^{\circ} \mathrm{C}$ for 24 hours prior to all experiments.

2.2. Atmospheric Pressure Plasma (APP) Treatment. APP colour-fading treatment was conducted by an atmospheric pressure plasma jet (APPJ, Surfx Technologies LLC, CA, USA) with a rectangular nozzle. After glow plasma was generated by radio frequency of $13.56 \mathrm{kHz}$. Helium (He) and oxygen $\left(\mathrm{O}_{2}\right)$ were used as carrier and reactive gas, respectively. Plasma operation parameters were set as jet distance $=3 \mathrm{~mm}$, oxygen concentration $=1 \%$, treatment time $=5 \mathrm{sec} / \mathrm{mm}$ (treating $1 \mathrm{~mm}$ of fabric with 5 seconds), and ignition power $=160 \mathrm{~W}$. Schematic diagram of the experimental setup was shown in Figure 1. 


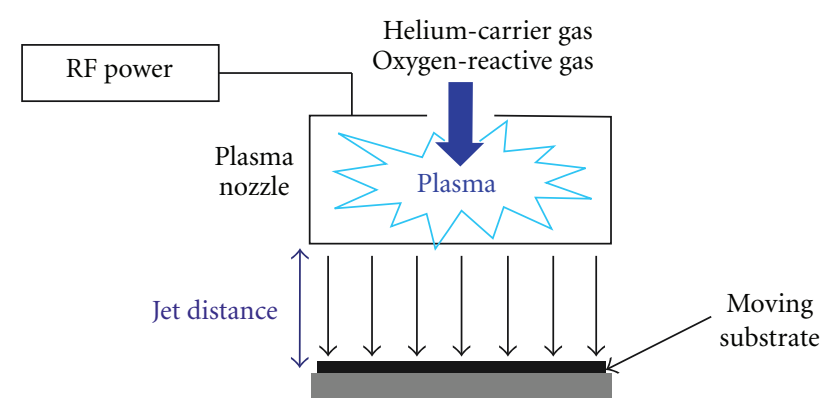

FIGURE 1: Schematic diagram of APP treatment.

2.3. Enzymatic Colour-Fading Process. Knitted fabric was cut into size of $22 \mathrm{~cm} \times 22 \mathrm{~cm}$ and was conditioned at $65 \pm 2 \%$ relative humidity and $21 \pm 1^{\circ} \mathrm{C}$ for at least 24 hours prior to enzyme treatment. A neutral enzyme (Lava Cell NNM, DyStar) with activity $130 \mathrm{EGU} / \mathrm{g}$ was used for treating the fabric. Enzyme treatment was carried out using a LaunderOmeter (Atlas Material Testing Technology LLC, Chicago, USA) which was rotated at a speed of 40-45 rpm. The fabric was treated with $0.1 \%$ (on weight of fabric) enzyme with a liquor ratio of $50: 1$ at $50^{\circ} \mathrm{C}$ for 30 minutes. The $\mathrm{pH}$ value of the enzyme treatment was set at 7.5 with buffer solution, and mechanical agitation was simulated by using 50 stainless steel balls of $6 \mathrm{~mm}$ diameter. After enzyme treatment, the fabrics were rinsed with deionized water to wash away abraded fibres attached on fabrics. The fabrics were then washed thoroughly with nonionic detergent $(1 \mathrm{~g} / \mathrm{L})$ with a liquor ratio $50: 1$ at $80^{\circ} \mathrm{C}$ for 10 minutes to deactivate the enzyme action and washed away unfixed dye from fabric surface. After that, the fabrics were rinsed with running water, squeezed to remove excessive water, and were dried completely in an oven at a temperature of $90^{\circ} \mathrm{C}$. After drying, the fabrics were placed for conditioning at $65 \pm 2 \%$ relative humidity and $21 \pm 1^{\circ} \mathrm{C}$ for at least 24 hours before further evaluations.

2.4. Measurement of Weight Change. The weight of fabric samples before and after treatment was measured by Shimadzu BX300 meter after conditioning at $21 \pm 1^{\circ} \mathrm{C}$ and relative humidity of $65 \pm 2 \%$ for 24 hours. The percent change of weight was calculated, after five measurements, as in the following:

$$
\text { Weight change }(\%)=\frac{W-W_{o}}{W_{o}} \times 100,
$$

where $W_{o}$ is the initial weight, and $W$ is the weight of the fabric sample after treatment.

2.5. Measurement of Colour. Colour properties of samples were measured by Macbeth Color Eye 7000A spectrophotometer. The conditions for measurement were specular excluded, large aperture with $10^{\circ}$ observer, and illuminant $\mathrm{D}_{65}$. The samples were measured twice, and colour yields (expressed by $K / S$ value) were obtained from the reflectance curve which were calculated according to (2). Finally, the sum value of $K / S$ (K/S Sum) was obtained by individual $K / S$ values over the visible spectrum ranging from wavelength of
TABLE 1: Weight change of different samples.

\begin{tabular}{lc}
\hline Fabric sample & Percentage weight change $(\%)^{*}$ \\
\hline APP-induced colour fading & -5.0 \\
Enzymatic colour fading & -10.0 \\
\hline
\end{tabular}

${ }^{*}$ Negative value refers to weight loss.

$400 \mathrm{~nm}$ to $700 \mathrm{~nm}$. The higher the $K / S$ Sum value, the higher the colour yield would be

$$
\frac{K}{S}=\frac{(1-R)^{2}}{2 R}
$$

where $K=$ absorption coefficient, depending on concentration of the colorant; $S$ = scattering coefficient, caused by the dyed substrate; and $R=$ reflectance of the coloured sample.

In addition, CIE colour coordinates, that is, $L^{*}$ (lightness and darkness), $a^{*}$ (redness and greenness), $b^{*}$ (yellowness and blueness), and $\Delta E$ (total colour difference) were measured.

\section{Results and Discussion}

3.1. Weight Change. Table 1 shows that percentage of weight changes after different treatments. The negative value in percentage weight change indicates that weight loss after treatment. In the enzymatic colour-fading, the action of enzyme and mechanical agitation will abrade fibre surface, and cotton fibre would be released resulting in weight reduction. As a result, after enzyme treatment, weight loss was observed because of the enzymatic hydrolysis which could not be avoided, but a high degree of enzymatic hydrolysis was not expected [10]. The hydrolysis is required to obtain the desired effect of colour removal. On the other hand, weight loss was also observed in the APP-induced colourfading process. During APP treatment, the fibre surface was subjected to localised ablation, and only surface etching would be resulted. On the whole, APP treatment introduces lower percentage weight loss than the enzyme treatment because the APP treatment affects only the surface of the material and no effect on the bulk properties of the materials.

3.2. Colour Properties. The $K / S$ Sum value is related to the concentration of the colorant in the fabric. $K / S$ Sum values of different fabrics are shown in Table 2. From the results, it is noted the differently treated fabrics have lower $K / S$ Sum values than the untreated fabric. Generally speaking, the higher the K/S Sum value, the higher the colour yield will be, and it can conclude that a paler shade was obtained after different treatments. The APP-treated fabric has a paler shade than the untreated fabric. The reason is that during the APP treatment, the oxygen plasma would oxidize the dyes in the fabric surface leading to a colour-fading effect [11]. However, in the case of enzymatic colour-fading treatment, the enzyme in the aqueous medium can penetrate effectively into the interior part of fabric. The enzymatic hydrolysis induced by enzyme in the fabric would be occurred $[12,13]$. More fibres on fabric are hydrolysed by enzyme, and the weaken fibres 
TABLE 2: Colour properties.

\begin{tabular}{|c|c|c|c|c|c|}
\hline Fabric sample & K/S Sum & $L^{*}$ & $a^{*}$ & $b^{*}$ & $\Delta E^{\#}$ \\
\hline Untreated & 435.63 & 22.94 & 1.66 & -3.20 & - \\
\hline APP-induced colour fading & 387.23 & 25.55 & 1.49 & -2.63 & 2.68 \\
\hline Enzymatic colour fading & 383.95 & 25.38 & 1.72 & -3.78 & 2.51 \\
\hline
\end{tabular}

${ }^{\#} \Delta E=\left[\left(\Delta L^{*}\right)^{2}+\left(\Delta a^{*}\right)^{2}+\left(\Delta b^{*}\right)^{2}\right]^{1 / 2}$.

$\Delta L^{*}=L_{\text {treated fabric }}^{*}-L_{\text {untreated fabric }}^{*}$

$\Delta a^{*}=a_{\text {treated fabric }}^{*}-a_{\text {untreated fabric }}^{*}$

$\Delta b^{*}=b_{\text {treated fabric }}^{*}-b_{\text {untreated fabric }}^{*}$.

are further removed by abrasion of fabric and mechanical agitation. Thus, more dye particles are removed with the cotton fibres. As a result, the enzyme-treated fabric gives a paler shade than the APP-treated fabric.

CIE colour coordinates include colour qualities in terms of $L^{*}$ (lightness and darkness), $a^{*}$ (redness and greenness), and $b^{*}$ (yellowness and blueness) of the fabrics are shown in Table 2. The higher the $L^{*}$ value is, the lighter the sample is. The $L^{*}$ values of differently treated fabrics were increased which indicates that the fabric lightness was increased after both APP and enzymatic colour-fading treatments. Since APP treatment is physically a surface etching process, the surface-protruding fibre in the fabric surface would be removed together with the dye leading to a smooth surface. In the case of enzyme, there are two factors contributing the increase in lightness induced by enzyme treatment. The first factor is that the enzyme action gives reactive-dyed cotton fabric an aged appearance (i.e., biostoning), while the second factor is to give cotton fabric a revived appearance by removing the surface fibre (i.e., depilling or biopolishing). Both factors contribute to change the lightness of the enzymetreated cotton fabric. During the action of enzyme and mechanical agitation, the depilling or biopolishing effect occurs at the fabric surface, and consequently the surface fibres were removed [14]. At the same time, the action of enzyme on the fibre surface would increase the smoothness and evenness. The smooth surface induced by enzyme would enhance the regular reflection of light from the fabric surface, and therefore the lightness was increased.

The $a^{*}$ value represents redness and greenness of the fabric sample. The more positive the value of $a^{*}$ is, the redder the shade of the sample will be. On the contrary, the value of $a^{*}$ being towards negative indicates the greenness of the shade of the sample. It is noted that APP-treated fabric have a reduction in $a^{*}$ value which indicates that fabric will turn greener than the untreated fabric. During the APP treatment, thermal oxidation effect may occur in the fabric surface leading to certain degree of yellowness [15]. The thermal induced yellow colour together with the original blue colour in the fabric surface would result in increased greenish effect. On the contrary, the $a^{*}$ value of enzyme-treated fabric increased slightly which indicates the redder shade was obtained after enzyme treatment. During the enzyme treatment, the hydrolysis of the cellulose would occur, and blue reactive dye would be released from the fibre and re-deposited on the fabric surface leading to a further colouring of fabric surface which may be termed as backstaining [16]. As a result, the $a^{*}$ value increased.
In general, the $b^{*}$ value describes the yellowness and blueness of a sample. The higher the positive value of $b^{*}$ is, the more will be the yellowish of the sample. On the contrary, negative value of $b^{*}$ refers to the bluish colour of the sample. It is revealed that the APP treatment increases the $b^{*}$ value because under the effect of oxygen plasma not only the reactive dye is removed due to the impact of active plasma particles (ions, free radicals, etc) with fibre [11], but also the thermal oxidation in fabric surface would induce certain degree of yellowness [15]. As a result, a yellowish shade would be imparted after APP treatment. With the use of enzyme treatment, the $b^{*}$ values of enzyme-treated fabric decrease further, that is, the $b^{*}$ values of the enzymetreated fabrics become more negative which indicates that the enzyme treatment can increase the bluish shade in the fabric. During the enzyme treatment, the hydrolysis of cellulose would occur, and the blue dye would be released from the fibre and redeposited on the surface of the fabric leading to backstaining [16]. As a result, $b^{*}$ value decreased.

Table 2 shows the $\Delta E$ values of differently treated fabrics. $\Delta E$ value contains the information of colour depth, shade, and the hue of a sample. $\Delta E$ value is calculated by using the CIE $L^{*}, a^{*}$, and $b^{*}$ values with the equation $\Delta E=\left(\Delta L^{* 2}+\Delta a^{* 2}+\Delta b^{* 2}\right)^{1 / 2}$ where $\Delta L^{*}, \Delta a^{*}$, and $\Delta b^{*}$ values were the difference between $L^{*}, a^{*}$, and $b^{*}$ values of a pair of colour standard and sample. The larger the $\Delta E$ value, the greater will be the colour difference between this pair of colour standard and sample. It was noted after the APP and enzyme treatments that colour difference was appeared between the control and the treated fabrics. This colour difference was expected because after the APP and enzyme treatment, changes in ${ }^{*} L, a^{*}$, and $b^{*}$ values were noted, and these three values would contribute the total colour difference values. However, it is interesting to note that the APP-induced and enzymatic colour-fading process obtain similar $\Delta E$ values. This finding can support the argument to use APP treatment as an alternative to conventional enzyme treatment to create colour-fading effect on textile fabric.

\section{Conclusion}

In the present study, the dyed cotton fabrics were subjected to APP-induced colour-fading process, and the colourfading effect was compared with conventional enzymatic colour-fading process. Experimental results revealed that APP treatment could achieve similar colour-fading effect when compared with conventional enzymatic colour-fading 
process without much loss in fabric weight and with shorter treatment time. Therefore, it could be concluded that with the careful control of the APP process parameters, APP treatment could be flexible as an alternative to conventional chemicalbased colour-fading process to be used in textile industry.

\section{Acknowledgment}

Authors would like to thank the financial support from the The Hong Kong Polytechnic University for this work.

\section{References}

[1] A. Card, M. A. Moore, and M. Ankeny, "Performance of garment washed denim blue jeans," AATCC Review, vol. 5, no. 6, pp. 23-27, 2005.

[2] M. Sariisik, "Use of cellulases and their effects on denim fabric properties," AATCC Review, vol. 4, no. 1, pp. 24-29, 2004.

[3] A. Cavaco-Paulo, "Mechanism of cellulase action in textile processes," Carbohydrate Polymers, vol. 37, no. 3, pp. 273-277, 1998.

[4] N. Ozdil, E. Ozdooan, and T. Oktem, "Effects of enzymatic treatment on various spun yarn fabrics," Fibres and Textiles in Eastern Europe, vol. 11, no. 4, pp. 58-61, 2003.

[5] R. Mori, T. Haga, and T. Takagishi, "Bending and shear properties of cotton fabrics subjected to cellulase treatment," Textile Research Journal, vol. 69, no. 10, pp. 742-746, 1999.

[6] A. S. Aly, A. B. Moustafa, and A. Hebeish, "Bio-technological treatment of cellulosic textiles," Journal of Cleaner Production, vol. 12, no. 7, pp. 697-705, 2004.

[7] C. Q. Yang, W. Zhou, G. C. Lickfield, and K. Parachura, "Cellulase treatment of durable press finished cotton fabric: effects on fabric strength, abrasion resistance, and handle," Textile Research Journal, vol. 73, no. 12, pp. 1057-1062, 2003.

[8] A. Cavaco-Paulo and M. Jose Rios, "Mechanical properties of cellulase-treated fabrics analyzed," American Dyestuff Reporter, vol. 86, no. 9, pp. 20-28, 1997.

[9] M. Montazer and A. S. Maryan, "Application of laccases with cellulases on denim for clean effluent and repeatable biowashing," Journal of Applied Polymer Science, vol. 110, no. 5, pp. 3121-3129, 2008.

[10] W. Rakowski, "Plasma treatment of wool today. Part 1: fibre properties, spinning and shrinkproofing," Journal of the Society of Dyers and Colourists, vol. 113, no. 9, pp. 250-255, 1997.

[11] M. Ghoranneviss, B. Moazzenchi, S. Shahidi, A. Anvari, and A. Rashidi, "Decolorization of denim fabrics with cold plasmas in the presence of magnetic fields," Plasma Processes and Polymers, vol. 3, no. 3, pp. 316-321, 2006.

[12] B. Dhurai and V. Natarajan, "Effect of enzyme softening of cotton hosiery yarns on knittability and dimensional properties of weft knitted fabrics," Indian Journal of Fibre and Textile Research, vol. 32, no. 2, pp. 241-247, 2007.

[13] C. W. Kan, C. W. M. Yuen, S. Q. Jiang, W. S. Tung, and S. Y. Cheng, "Influence of enzymatic treatment on the properties of linen," Journal of Applied Polymer Science, vol. 104, no. 1, pp. 286-289, 2007.

[14] K. J. Vishnu Vardhini and N. Selvakumar, "Biopolishing enzymes and their influence on the properties of cotton materials-a review," Colourage, vol. 53, no. 12, pp. 45-52, 2006.
[15] C. W. Kan, C. W. M. Yuen, and W. Y. Tsoi, "Using atmospheric pressure plasma for enhancing the deposition of printing paste on cotton fabric for digital ink-jet printing," Cellulose, vol. 18, no. 3, pp. 827-839, 2011.

[16] C. W. Kan and W. Y. Wong, "Color properties of cellulasetreated cotton denim fabric manufactured by torque-free ring spun yarn," Textile Research Journal, vol. 81, no. 9, pp. 875-882, 2011. 

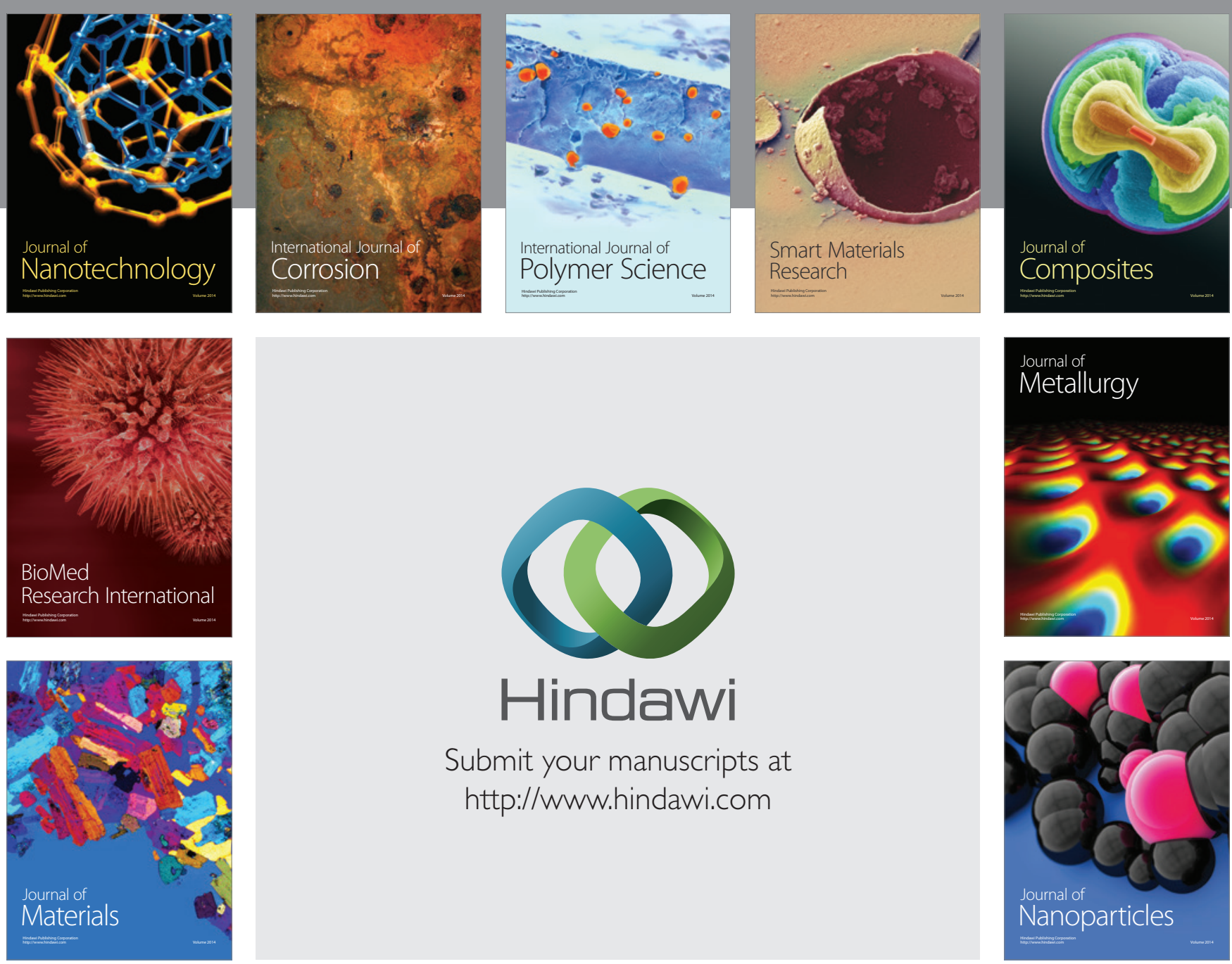

Submit your manuscripts at http://www.hindawi.com
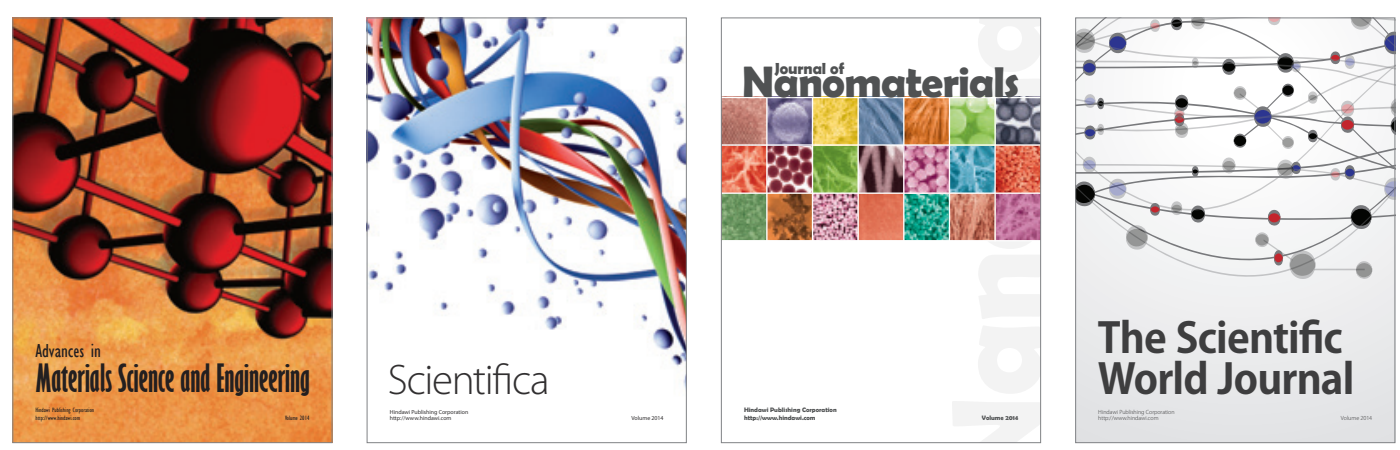

\section{The Scientific World Journal}
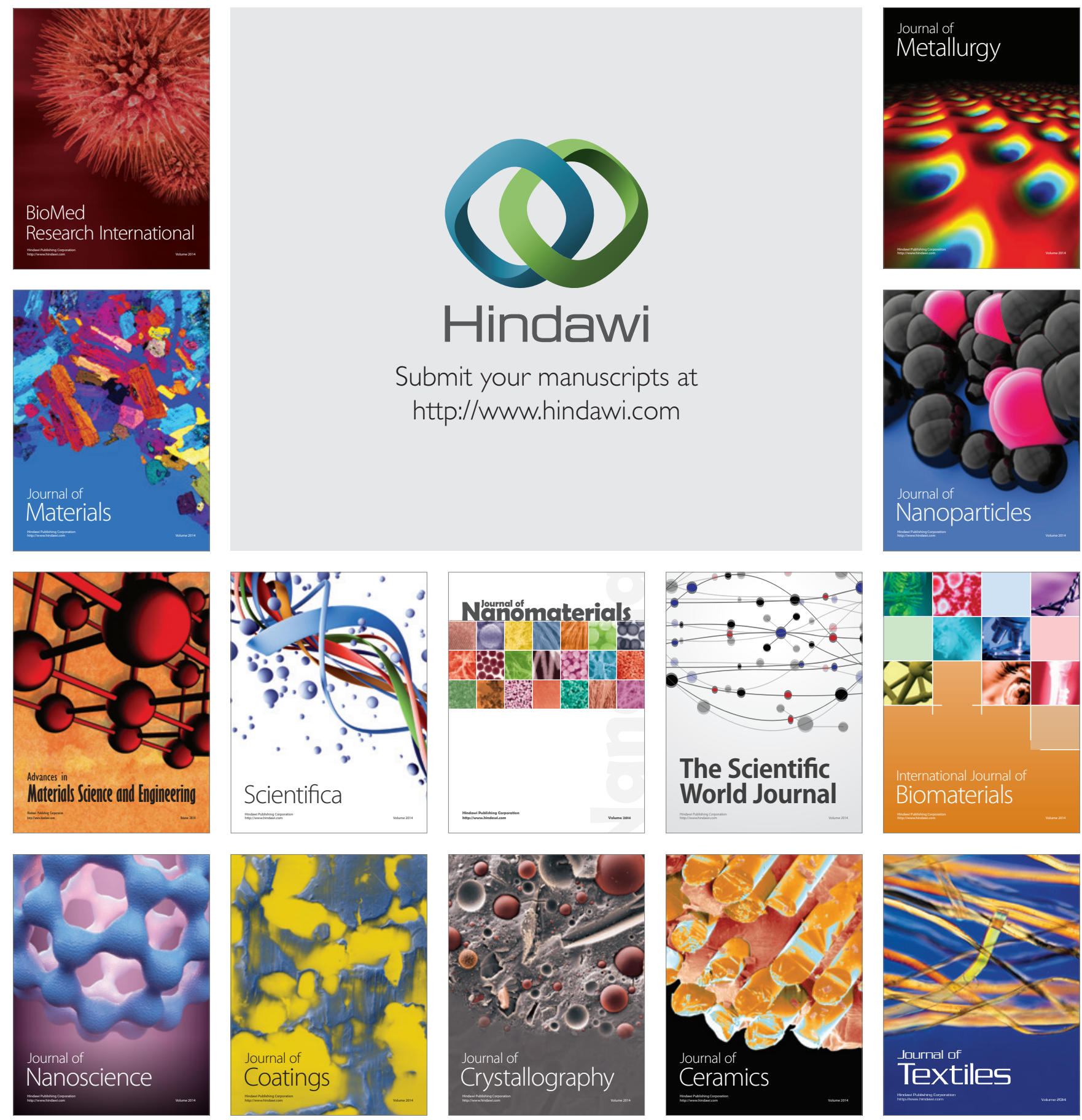